\title{
Increased risk of joint failure in hip prostheses infected with Staphylococcus aureus treated with debridement, antibiotics and implant retention compared to Streptococcus
}

\author{
Michael Betz • Sophie Abrassart • Pierre Vaudaux • \\ Ergys Gjika • Maximilian Schindler • Julien Billières • \\ Besa Zenelaj • Domizio Suvà • Robin Peter • Ilker Uçkay
}

Received: 13 July 2014 / Accepted: 12 August 2014 /Published online: 4 September 2014

(C) SICOT aisbl 2014

\begin{abstract}
Purpose The debridement, antibiotic and implant retention (DAIR) procedure is an option for patients with prosthetic hip joint infections for whom arthroplasty removal is problematic. Unfortunately, some of the guidelines proposed for deciding on DAIR management of arthroplasty infections fail to take into consideration the role of the infecting pathogen. While Staphylococcus aureus and streptococci are major contributors to infected hip arthroplasties, their respective contributions to treatment success or failure rates with the DAIR procedure have not been thoroughly analysed from a microbiological perspective.

Methods This retrospective study included all patients who were hospitalised in Geneva University Hospitals between 1996 and 2012 and were initially treated with DAIR for prosthetic hip joint monomicrobial infection due to $S$. aureus or Streptococcus spp. The outcome of DAIR treatment was evaluated after a minimal follow-up of two years. A literature search was also performed to retrieve data from additional DAIR-treated cases in other institutions.

Results In our institution, 38 DAIR-treated patients with hip arthroplasty monomicrobial infections underwent at least one
\end{abstract}

Parts of the manuscript have been presented as posters at the 4th OPIC Meeting, 2-4 April 2014, Oxford, UK and at the Annual Meeting 2014 of the Swiss Society for Infectious Diseases, 28-29 August, Aarau, Switzerland.

M. Betz $\cdot$ S. Abrassart $\cdot$ E. Gjika $\cdot$ M. Schindler $\cdot$ J. Billières $\cdot$

B. Zenelaj $\cdot$ D. Suvà $\cdot$ R. Peter $\cdot$ I. Uçkay

Orthopedic Surgery Service, Geneva University Hospitals \& Medical

School, University of Geneva, Geneva, Switzerland

P. Vaudaux $・$ I. Uçkay $(\bowtie)$

Service of Infectious Diseases, Geneva University Hospitals \&

Medical School, University of Geneva, Geneva, Switzerland

e-mail: ilker.uckay@hcuge.ch surgical debridement (median two, range one to five), exchange of mobile parts and concomitant targeted antibiotic therapy for several weeks or months. A literature search identified outcome data in other institutions from 52 additional DAIR-treated cases according to our study criteria. After merging our own data with those retrieved from other reports, we found a failure rate of $21 \%$ instead of $24 \%$ for $S$. aureusinfected, DAIR-treated patients, but no failure in 14 streptococcal-infected patients. In the pooled data, the failure rate linked with $S$. aureus infections was significantly higher than that with Streptococcus ssp. (19/90 vs 0/14 episodes; Fisher's exact test, $P=0.07$ ).

Conclusions DAIR-treated patients with prosthetic hip joint infections due to $S$. aureus tended to have worse outcomes than those infected with Streptococcus spp. The specific influence of the infecting pathogen should be considered in future guidelines and recommendations.

Keywords Total hip arthroplasty $\cdot$ Infection · Retention · Streptococci $\cdot$ Staphylococcus aureus

\section{Introduction}

Among the different approaches used for the management of infected joint prostheses [1], the one- or two-stage exchanges are the preferred options for remission. Nevertheless, for patients with advanced age, severe co-morbidities [2] and anticipated anaesthesiological problems [3, 4], or for acute infections occurring within less than three to four weeks, a debridement, prolonged antibiotics and implant retention (DAIR) approach $[1,4-7]$ may be attempted following experts' recommendations. Contraindications for DAIR are considered the presence of a sinus tract, implant loosening and maybe delay in 
debridement for more than one month [3]. Infection due to methicillin-resistant Staphylococcus aureus (MRSA) could also worsen the prognosis [5] because of the limited availability of bactericidal antibiotics and potential emergence of glycopeptide resistance in vancomycin-treated patients [8].

Unfortunately, some of the guidelines proposed for deciding on DAIR management of osteoarticular infections, with $[1,9]$ or without implants [10], fail to take into consideration the role of the infecting pathogen (besides its methicillin resistance) [1]. This is surprising in view of data indicating a more difficult eradication of $S$. aureus compared to Streptococcus spp. infections $[4,6,7]$. We recently reported that for DAIR-treated prosthetic total knee joint infections failure rates for $S$. aureus-infected patients were nearly five times higher than those due to streptococci [11]. Using a similar approach, this study reports the outcome of DAIR treatment in prosthetic hip infections due to $S$. aureus compared to Streptococcus spp. To extend the significance of the study, we pooled data from our institution with those from other DAIR-treated cases retrieved from the literature.

\section{Methods, criteria and analyses}

We included all patients hospitalised in our institution from 1996 to 2012 for an infection of total hip arthroplasty or hemiarthroplasty who met criteria for DAIR treatment. Exchange of mobile parts of the prostheses was allowed according to the study definition and routinely performed in our institution. Only the first episodes of $S$. aureus or Streptococcus spp. infections were included. Exclusion criteria were recurrent episodes, treatment by implant removal, pathogens other than S. aureus or Streptococcus spp., culture-negative and mixed infections. A minimal active follow-up of two years was required. Remission was defined as the absence of clinical, radiological and laboratory signs of infection during the two year follow-up or later on. Failure was defined by the persistence or recurrence of infections. The design of our retrospective study was approved by our local Ethics Committee (Arthroplasty Cohort, no. 08-057).

To extend the significance of our study, we retrieved from the literature outcome data from patients with hip arthroplasty infections who were treated with DAIR in other institutions, by using the same search criteria (except for time restriction of follow-up periods) as for our study. These data were retrieved from PubMed and other public websites, in particular various national arthroplasty registers in English, French, German and Turkish languages, by focusing on studies with a specific stratification of pathogens linked to DAIR and hip prostheses.

Group comparisons were performed by using the Wilcoxon rank sum test for continuous variables or Fisher's exact test for categorical variables. Due to the small number of failures scored as outcome variable, there was no possibility for case-mix adjustment in a multivariate model. $P$ values $\leq 0.05$ (two-tailed) were significant. Stata ${ }^{\mathrm{TM}}$ software (version 9.0, StataCorp, College Station, TX, USA) was used.

\section{Results}

A total of 38 monomicrobial episodes of hip arthroplasty infections occurring in 38 DAIR-treated patients were retrieved in our institution (Table 1). Of the episodes, 12 were due to methicillin-susceptible $S$. aureus, 17 to MRSA and nine to various species of streptococci (S. bovis, S. pyogenes, S. agalactiae). The median follow-up was 3.5 years (range 2.2-9.8 years), during which seven treatment failures (18\%) occurred, after a median post-therapy period of 50 days. The patient populations with remission and failure were equally balanced (Table 1). While the median delay between initial prosthesis implantation and first debridement for infection was not different between remissions and failures $(23$ vs 34 days, Table 1), it was significantly shorter for staphylococcal compared to streptococcal infections ( 0.5 vs 24 months, $P=0.003$ ).

All patients underwent at least one surgical debridement (median two, range one to five), exchange of mobile parts of the arthroplasty and concomitantly received pathogendirected antimicrobial therapy for a median duration of 12 weeks (range 4.3-28.7 weeks), with an initial phase of intravenous administration for a median period of 14 days.

While there was a trend for a higher failure rate in the group of DAIR-treated hip joint prostheses infected with $S$. aureus compared to Streptococcus spp., this difference did not reach statistical significance due to the small sample size (Fisher's exact test, $7 / 31$ vs $0 / 9$ episodes, $P=0.32$ ). A similar lack of statistical significance was equally observed when comparing failure rates due to methicillin-susceptible $S$. aureus alone compared to Streptococcus spp. [2/21 vs 0/9 episodes, odds ratio (OR) 0.3, $95 \%$ confidence interval (CI) 0.02-1.92, $P=$ $0.50]$. When increasing our database by adding 52 additional cases reported in the literature, a significant difference was detected between $S$. aureus and streptococcal DAIR-treated infections (19/90vs 0/14 episodes, OR 0, $95 \%$ CI 0-0.86, $P=$ 0.07 ) (Table 2). In contrast to the significant failure rate that occurred in $21 \%$ of the DAIR $S$. aureus-infected patients, no failure was recorded among the 14 streptococcal hip arthroplasty infections.

\section{Discussion}

When merging our own clinical data with those from other reports, the success rates of the DAIR treatment for infected hip arthroplasties were significantly influenced by the nature of the pathogens. Indeed, the DAIR protocol led to an average 
Table 1 Clinical variables associated with failure of infected hip prostheses in hospitalised patients at Geneva University Hospitals

\begin{tabular}{|c|c|c|c|}
\hline & Remission, $n=31$ & $P^{\mathrm{a}}$ & Failure, $n=7$ \\
\hline Female gender & $17(55 \%)$ & 1.00 & $4(57 \%)$ \\
\hline Median age & 75 years & 0.22 & 83 years \\
\hline Immune suppression $^{\mathrm{b}}$ & $14(45 \%)$ & 0.21 & $1(14 \%)$ \\
\hline Staphylococcus aureus & $22(71 \%)$ & 0.16 & $7(100 \%)$ \\
\hline Methicillin sensitive & $19(61 \%)$ & 0.21 & $2(29 \%)$ \\
\hline Methicillin resistant & $12(39 \%)$ & 0.21 & $5(71 \%)$ \\
\hline Streptococcus spp. & $9(29 \%)$ & 0.16 & $0(0 \%)$ \\
\hline Bacteremia & $8(26 \%)$ & 0.39 & $3(43 \%)$ \\
\hline Sinus tract & $2(6 \%)$ & 0.47 & $0(0 \%)$ \\
\hline Implant loosening & $0(0 \%)$ & - & $0(0 \%)$ \\
\hline Median delay between prosthesis implantation and debridement & 23 days & 0.63 & 34 days \\
\hline Median number of surgical interventions & 2 & 0.08 & 2 \\
\hline Median duration of antibiotic therapy & 12 weeks & 0.22 & 9 weeks \\
\hline Rifampicin use & $18(58 \%)$ & 0.68 & $5(71 \%)$ \\
\hline
\end{tabular}

${ }^{\text {a }} P$ values $\leq 0.05$ are significant

${ }^{\mathrm{b}}$ Diabetes mellitus, Child class $\mathrm{C}$ cirrhosis, active cancer

$21 \%$ failure rate in S. aureus-infected patients compared to a much lower failure rate with monomicrobial streptococcal infections. These findings are similar to those previously reported for infected knee prostheses where streptococci led to a lower DAIR failure risk than S. aureus [11]. These data lend support to the inclusion of the pathogen nature in clinical guidelines for DAIR decisions, in particular the presence of S. aureus (even if methicillin-susceptible) or Streptococcus spp. as a specific, additional risk factor besides implant loosening, fistulas, soft tissue aspects, antibiotic resistance and co-morbidities.
The enhanced adherence capacity of S. aureus to implants lies in its virulence factors [12], the ability to form biofilms [13] and to adapt locally, e.g. by transformation into small colony variants [14], once infection has been established. In contrast, streptococci, especially of the $\beta$-haemolytic group, prefer rather an arsenal for rapid spread inside soft tissues and fascia $[15,16]$ than formation of abscesses or biofilms. With these microbiological differences in mind, our results are not surprising. Moreover, other authors [6, 7], even if not all [17], equally mention a worse outcome of staphylococci in cases of DAIR. To cite an example, colleagues from the Mayo Clinic

Table 2 Comparison of our results with similar cases in the literature

\begin{tabular}{|c|c|c|c|c|c|c|c|}
\hline & & $\begin{array}{l}\text { Remission, } \\
n=71\end{array}$ & $\begin{array}{l}\text { Failure, } \\
n=19\end{array}$ & $\begin{array}{l}\text { Median age } \\
\text { (years) }\end{array}$ & $\begin{array}{l}\text { Minimal duration } \\
\text { of antibiotic therapy }\end{array}$ & $\begin{array}{l}\text { Median no. of } \\
\text { debridements }\end{array}$ & $\begin{array}{l}\text { Minimal } \\
\text { follow-up }\end{array}$ \\
\hline \multirow[t]{2}{*}{ Our study } & S. aureus & 22 & 7 & 78 & 6 weeks & 2 & 3 years \\
\hline & Streptococci & 9 & 0 & 78 & 4.3 weeks & 1 & 4.4 years \\
\hline Aboltins et al. [22] & S. aureus & 10 & 1 & 75 & 12 months & 2.2 & 1 year \\
\hline \multirow[t]{2}{*}{ Soriano et al. [23] } & S. aureus & 5 & 0 & 76 & 2.7 months & - & 2 years \\
\hline & Streptococci & 2 & 0 & - & 2.7 months & - & 2 years \\
\hline Drancourt et al. [24] & S. aureus & 3 & 3 & - & 6 months & - & 2.8 years \\
\hline Barberan et al. [5] & S. aureus & 10 & 5 & 75 & 1.5 months & - & 0.5 years \\
\hline \multirow[t]{2}{*}{ Segreti et al. [25] } & S. aureus & 2 & 1 & 59 & 58 months & - & 5 years \\
\hline & Streptococci & 1 & 0 & 74 & 49 months & - & 5 years \\
\hline \multirow[t]{2}{*}{ Sukeik et al. [3] } & S. aureus & 5 & 2 & 66 & 1.5 months & 1.4 & 5 years \\
\hline & Streptococci & 2 & 0 & - & 1.5 months & 1 & 5 years \\
\hline \multirow[t]{2}{*}{ Overall } & S. aureus & 57 & 19 & & & & \\
\hline & Streptococci & 14 & 0 & & & & \\
\hline
\end{tabular}


attributed a remission of only $13 \%$ for prosthetic joint infections due to $S$. aureus [4], in contrast to $79 \%$ for streptococci, which reveals a worse outcome than in our database with $79 \%$ success for $S$. aureus.

The main limitation of this study is the small sample size of 90 documented and published monomicrobial episodes, which were pooled from our institution with additional cases retrieved from small case series performed in other institutions. Unfortunately, a large number of reports addressing DAIR problems failed to provide detailed numbers of episodes treated for each pathogen, in particular S. aureus [18], or to report the number of hip arthroplasty infections associated with $S$. aureus separately $[1,2,4,7,17,19]$ from those involving other joint prostheses $[1,4,6,20]$, although this information is likely present in their databases. Further multicentre studies including a more open access to those available registers could provide a most welcome benefit for both clinicians and investigators. A second limitation to our study was the decision to analyse exclusively monomicrobial infections due to $S$. aureus or Streptococcus spp. Hence, our conclusion is invalid for mixed infections or other pathogens that are potentially difficult to eradicate such as Pseudomonas spp. [20, 21]. Finally, all of the Genevian patients, in both populations, had mobile parts of their prostheses changed, while this information was inconsistently available in the literature. Both staphylococcal and streptococcal infections benefit from this approach, because mobile part exchanges were performed according to local procedures independently of the pathogen that was unknown at the time of debridement. Consequently, we are formally unable to pass judgment on the role of this surgical approach. Therefore, while exchanging mobile parts might per se be a protective factor regarding DAIR failure, we believe nevertheless that it has no substantial interaction with underlying microorganisms.

Acknowledgments We thank Prof. Benjamin A. Lipsky, the Orthopedic Service and the Laboratory of Microbiology for their support.

Conflict of interest The authors declare that they have no conflict of interest.

\section{References}

1. Giulieri SG, Graber P, Ochsner PE, Zimmerli W (2004) Management of infection associated with total hip arthroplasty according to a treatment algorithm. Infection 32:222-228

2. Tattevin P, Crémieux AC, Pottier P, Huten D, Carbon C (1999) Prosthetic joint infection: when can prosthesis salvage be considered? Clin Infect Dis 29:292-295

3. Sukeik M, Patel S, Haddad FS (2012) Aggressive early debridement for treatment of acutely infected cemented total hip arthroplasty. Clin Orthop Relat Res 470:3164-3170

4. Marculescu CE, Berbari EF, Hanssen AD, Steckelberg JM, Harmsen SW, Mandrekar JN et al (2006) Outcome of prosthetic joint infections treated with debridement and retention of components. Clin Infect Dis 42:471-478

5. Barberan J, Aguilar L, Carroquino G, Giménez MJ, Sánchez B, Martínez D et al (2006) Conservative treatment of staphylococcal prosthetic joint infections in elderly patients. Am J Med 119:7-10

6. Kuiper JW, Vos SJ, Saouti R, Vergroesen DA, Graat HCA, DebetsOssenkopp YJ et al (2013) Prosthetic joint-associated infections treated with DAIR (debridement, antibiotics, irrigation, and retention): analysis of risk factors and local antibiotic carriers in 91 patients. Acta Orthop 84:380-386

7. Byren I, Bejon P, Atkins BL, Angus B, Masters S, McLardy-Smith P et al (2009) One hundred and twelve infected arthroplasties treated with 'DAIR' (debridement, antibiotics and implant retention): antibiotic duration and outcome. J Antimicrob Chemother 63:1264-1271

8. Vaudaux P, Ferry T, Uçkay I, François P, Schrenzel J, Harbarth S et al (2012) Prevalence of isolates with reduced glycopeptide susceptibility in orthopedic device-related infections due to methicillin-resistant Staphylococcus aureus. Eur J Clin Microbiol Infect Dis 31:33673374

9. Al-Mayahi M, Betz M, Müller DA, Stern R, Tahintzi P, Bernard L et al (2013) Remission rate of implant-related infections following revision surgery after fractures. Int Orthop 37:2253-2258

10. Uçkay I, Jugun K, Gamulin A, Wagener J, Hoffmeyer P, Lew D (2012) Chronic osteomyelitis. Curr Infect Dis Rep 14:566-575

11. Zürcher-Pfund L, Uçkay I, Legout L, Gamulin A, Vaudaux P, Peter R (2013) Pathogen-driven decision for implant retention in the management of infected total knee prostheses. Int Orthop 37:1471-1475

12. Post V, Wahl P, Uçkay I, Ochsner P, Zimmerli W, Corvec S et al (2014) Phenotypic and genotypic characterisation of Staphylococcus aureus causing musculoskeletal infections. Int J Med Microbiol 304:565-576

13. Uçkay I, Pittet D, Vaudaux P, Sax H, Lew DP, Waldvogel F (2009) Foreign body infections due to Staphylococcus epidermidis. Ann Med 41:109-119

14. Vaudaux P, Kelley WL, Lew DP (2006) Staphylococcus aureus small colony variants: difficult to diagnose and difficult to treat. Clin Infect Dis 43:968-970

15. Chargui M, Uçkay I, Suvà D, Christofilopoulos P, Lomessy A, Pittet D (2014) Deep soft tissue infections. Rev Med Suisse 10:920-924

16. Sendi P, Christensson B, Uçkay I, Trampuz A, Remschmidt C, Boggian K et al (2011) Group B streptococcus in prosthetic hip and knee joint-associated infections. J Hosp Infect 79:64-69

17. Odum SM, Fehring TK, Lombardi AV, Zmistowski BM, Brown NM, Luna JT et al (2011) Irrigation and debridement for periprosthetic infections: does the organism matter? J Arthroplasty 26:114-118

18. Crockarell JR, Hanssen AD, Osmon DR, Morrey BF (1998) Treatment of infection with débridement and retention of the components following hip arthroplasty. J Bone Joint Surg Am 80:13061313

19. Azzam KA, Seeley M, Ghanem E, Austin MS, Purtill JJ, Parvizi J (2010) Irrigation and debridement in the management of prosthetic joint infection: traditional indications revisited. J Arthroplasty 25: $1022-1027$

20. Cobo J, Miguel LG, Euba G, Rodríguez D, García-Lechuz JM, Riera $\mathrm{M}$ et al (2011) Early prosthetic joint infection: outcomes with debridement and implant retention followed by antibiotic therapy. Clin Microbiol Infect 17:1632-1637

21. Seghrouchni K, van Delden C, Dominguez D, Benkabouche M, Bernard L, Assal M et al (2012) Remission after treatment of osteoarticular infections due to Pseudomonas aeruginosa versus Staphylococcus aureus: a case-controlled study. Int Orthop 36: 1065-1071

22. Aboltins CA, Page MA, Buising KL, Jenney AWJ, Daffy JR, Choong FM et al (2007) Treatment of staphylococcal prosthetic joint infections with debridement, prosthesis retention and oral rifampicin and fusidic acid. Clin Microbiol Infect 13:586-591 
23. Soriano A, García S, Bori G, Almela M, Gallart X, Macule F et al (2006) Treatment of acute post-surgical infection of joint arthroplasty. Clin Microbiol Infect 12:930-933

24. Drancourt M, Stein A, Argenson JN, Zannier A, Curvale G, Raoult D (1993) Oral rifampin plus ofloxacin for treatment of Staphylococcus- infected orthopedic implants. Antimicrob Agents Chemother 37: $1214-1218$

25. Segreti J, Nelson JA, Trenholme GM (1998) Prolonged suppressive antibiotic therapy for infected orthopedic prostheses. Clin Infect Dis $27: 711-713$ 